\title{
AÇÃO FISCALIZATÓRIA DO USO DE AGROTÓXICOS EM PROPRIEDADES RURAIS DA REGIÃO DE CRUZ ALTA - RIO GRANDE DO SUL
}

\author{
Gracieli Manfrin da Silva Erthal ${ }^{*}$, Eduardo Santos Erthal $^{2}$, Alexandre Russini $^{3}$, Gabriel Costa Spengler ${ }^{1}$, \\ Marcelo Silveira de Farias 4 \\ 1 Secretaria Estadual da Agricultura, Pecuária e Desenvolvimento Rural - SEAPDR, 98005-129, Cruz Alta, Brasil. \\ 2 Curso de Engenharia Ambiental e Sanitária. Universidade de Cruz Alta-UNICRUZ, 98020-290, Cruz Alta, Brasil. \\ 3 Campus Itaqui, Universidade Federal do Pampa, 97650-000, Itaqui, Brasil. \\ 4 Departamento de Ciências Agronômicas e Ambientais, Universidade Federal de Santa Maria, Campus de Frederico Westphalen, \\ 98400-000, Frederico Westphalen, Brasil.
}

*E-mail: gracieli-silva@agricultura.rs.gov.br

\section{RESUMO}

Conforme disposto no Art. 10 da Lei Federal no 7.802/89, cabe aos estados fiscalizarem o uso, o consumo, o comércio, o armazenamento e o transporte interno de agrotóxicos. Nesse contexto, o presente trabalho teve por objetivo apresentar a avaliação da ação fiscalizatória do uso de agrotóxicos e afins e o cumprimento da legislação em propriedades rurais da região delimitada pela Regional de Cruz Alta, RS no âmbito da Secretaria da Agricultura, Pecuária e Desenvolvimento Rural. Foram analisados os documentos fiscais emitidos pelos Fiscais Estaduais Agropecuários em fiscalização de uso de agrotóxicos e afins pela Secretaria da Agricultura, Pecuária e Desenvolvimento Rural, no período de 2012 a 2018. Os maiores problemas encontrados nas propriedades rurais da região são: a falta de depósito de agrotóxicos exclusivo para este fim; a falta do hábito de guardar os receituários agronômicos, notas fiscais e comprovantes de devolução das embalagens vazias; e a falta de depósito para armazenar as embalagens vazias de agrotóxicos. A infração de maior incidência foi a de manipular, importar, comercializar ou utilizar agrotóxicos e afins não registrados no Ministério da Agricultura Pecuária e Abastecimento (ilegais e banidos). Diante do panorama exposto, justificam-se ações de orientação e fiscalização, assim como atividades frequentes de educação sanitária nas propriedades rurais da região.

Palavras-chave: Fiscalização Agropecuária. Utilização de Agrotóxicos. Lei dos agrotóxicos. Agrotóxicos ilegais.

\section{Introdução}

A prática da agricultura remonta há mais de 10 mil anos, no entanto, a agricultura tradicional sofreu uma série de mudanças ao longo desse período. A inserção de novas tecnologias no processo de produção agrícola brasileiro foi com o intuito de aumentar a produtividade e intensificar o cultivo das commodities agrícolas. Nesse contexto, após a Segunda Guerra Mundial, o uso intensivo de agrotóxicos teve seu início marcado pela chamada Revolução Verde [1].

No Brasil, esse movimento chegou em 1960 e ganhou ênfase em 1970 com a criação do Programa Nacional de Defensivos Agrícolas (PNDA), que vinculava o uso de agrotóxicos à concessão de créditos agrícolas [2]. Além disso, o modelo de desenvolvimento da agricultura, baseado no agronegócio, com cultivo de culturas destinadas à exportação em larga escala, fazendo uso de grandes extensões de terra, tornou o uso de agrotóxicos uma prática cultural de grande relevância para a economia e sucesso da produção [3].

Os agrotóxicos são comercializados com o objetivo de contribuir para o processo de produção agrícola, principalmente quando se trata de produções em larga escala. Esses produtos atuam na prevenção e controle de pragas nas culturas, sendo um insumo de grande importância para a manutenção da sanidade dos cultivos. No entanto, em contrapartida, seu uso trás riscos que podem comprometer o meio ambiente e os indivíduos que tenham de algum modo, contato direto ou indireto com esses produtos [4].

Conforme destaca Souza [5], os efeitos no meio ambiente e na saúde humana que passaram a ser investigados cientificamente e sentidos pelos usuários desencadearam um 
cenário de pressões da sociedade, buscando um regramento mais rigoroso na produção, comercialização e uso de agrotóxicos no Brasil, o que até então era barrado pelo prevalecimento dos interesses das multinacionais fabricantes.

Diante desse cenário, foi criada a Lei Federal no 7.802/89, conhecida como Lei dos Agrotóxicos, a qual foi regulamentada pelo Decreto Federal 4.074/2002, que regulam, atualmente no Brasil, a pesquisa, a experimentação, a produção, a embalagem e rotulagem, o transporte, o armazenamento, a comercialização, a propaganda comercial, a utilização, a importação, a exportação, o destino final dos resíduos e embalagens, o registro, a classificação, o controle, a inspeção e a fiscalização de agrotóxicos, seus componentes e afins.

De acordo com Franco e Palaez [6], ao substituir o Decreto Federal n 24.114 de 1934, a Lei dos Agrotóxicos possibilitou uma enorme evolução institucional, proporcionando melhor qualidade de vida à população, considerando a proteção à saúde humana e a proteção ao meio ambiente. Dentre os avanços alcançados, destaca-se a obrigatoriedade do receituário agronômico para a comercialização de agrotóxicos, o que anteriormente estava disposto apenas em normas de alguns estados, nomeadamente o Rio Grande do Sul.

Segundo Rigotto, Vasconcellos e Rocha [7], o mercado de agrotóxicos do Brasil teve uma expansão de $190 \%$ na última década, levando o nosso país a assumir o $1^{\circ}$ lugar no ranking mundial de consumo dessas sustâncias, desde 2008. De acordo com dados do Boletim anual de 2017 do Instituto Brasileiro do Meio Ambiente e dos Recursos Naturais Renováveis - IBAMA [8], foram comercializados 539.944,95 ton. de ingrediente ativo, sendo o Centro-Oeste responsável por $33,1 \%$ desse montante, seguido pela região Sul com 30,6\% e Sudeste com $21,9 \%$. Nesse cenário, destacam-se os estados do Mato Grosso do Sul, com 18,6\% do montante brasileiro, seguido de São Paulo com 14,3\% e, em terceiro lugar, o estado do Rio Grande do Sul com $13 \%$.

Barroso e Wolff [9] ressaltam a importância do uso correto dos agrotóxicos, considerando que a aplicação incorreta desses produtos, além de gerar prejuízos, pode acarretar resistência das pragas e aumentar de forma considerável os riscos de contaminação do ambiente e dos indivíduos. Assim, para evitar o uso inadequado, acidentes e contaminações, os cuidados com os agrotóxicos devem ser observados em todas as etapas, desde a aquisição do produto com observação da receita agronômica, transporte e armazenamento, com observação da ABNT NBR 9.843-3 e da Norma Regulamentadora 31, manuseio e aplicação, com observação das recomendações constantes no receituário agronômico e na bula dos produtos, bem como no descarte dos resíduos e embalagens vazias, considerando em todas essas etapas o disposto na Lei dos Agrotóxicos.

Conforme disposto no Art. 10 da referida lei, cabe aos estados legislar sobre o uso, a produção, o consumo, o comércio e o armazenamento dos agrotóxicos, assim como fiscalizar o uso, o consumo, o comércio, o armazenamento e o transporte interno desses produtos. O Decreto Federal n 4.074/2002, no Art. 71, inciso II, institui que a fiscalização de agrotóxicos é da competência dos órgãos estaduais, responsáveis pelos setores da agricultura, saúde e meio ambiente, no âmbito de sua área de competência. Ainda, cabe ao estado fiscalizar o uso e o consumo de agrotóxicos, estabelecimentos de comercialização, armazenamento e prestação de serviços na aplicação de agrotóxicos, devolução e destinação adequada de embalagens vazias de agrotóxicos, produtos apreendidos em ação fiscalizatória, impróprios para uso ou em desuso, transporte de agrotóxicos e coletas de amostras para análise de fiscalização, assim como averiguação de resíduos de agrotóxicos em produtos agrícolas e seus subprodutos.

Nesse contexto, o presente trabalho teve por objetivo apresentar a avaliação da ação fiscalizatória do uso de agrotóxicos e afins e o cumprimento da legislação em propriedades rurais da região delimitada pela Regional de Cruz Alta, RS no âmbito da Secretaria da Agricultura, Pecuária e Desenvolvimento Rural (SEAPDR).

\section{Metodologia}

O presente estudo foi realizado na região delimitada pela Regional de Cruz Alta, RS no âmbito da SEAPDR, a qual divide o estado do Rio Grande do Sul em 19 Regionais distintas. A Regional de Cruz Alta é composta por 19 municípios que se localizam nas mesorregiões Noroeste e Centro-Oriental Rio Grandense.

A regional apresenta área de 877.544,3 hectares e, desses, 721.711 hectares foram cultivados em 2017 com culturas temporárias [10]. A área divide-se em 12.257 propriedades rurais distribuídas nos 19 municípios, delimitando-se a norte pelo município de Condor (28²'24,9”'S e 5335'10,4”W, coordenadas do limite Norte), a sul pelo município de Estrela Velha (29²1'53' $\mathrm{S}$ e $53^{\circ} 11^{\prime} 51,7^{\prime}$ ' W, coordenadas do limite Sul), a oeste pelo município de Boa Vista do Cadeado (28 $46^{\prime} 45^{\prime \prime} \mathrm{S}$ e $53^{\circ} 59^{\prime} 10,3^{\prime \prime}$ $\mathrm{W}$, coordenadas do limite Oeste), e a leste pelo município de NãoMe-Toque $\left(28^{\circ} 30^{\prime} 41,8^{\prime \prime} \mathrm{S}\right.$ e $52^{\circ} 41^{\prime} 10,2^{\prime}$ ' W, coordenadas do limite Leste), conforme Figura 1.

O município com maior número de propriedades rurais da regional é Ibirubá, com 1.398 propriedades, seguido de Panambi, com 904 e Tunas com 892, segundo Censo Agropecuário de 2006 [11]. Das 12.257 propriedades, foram fiscalizadas, no período considerado, de 2012 a 2018, 102 propriedades, escolhidas aleatoriamente, representando $0,83 \%$ do total. Sendo que nos anos de 2012 foram fiscalizadas apenas quatro propriedades e em 2014 apenas duas. Já em 2015, 2016, 2017 e 2018 foram fiscalizadas 23, 14, 16, 43 propriedades, respectivamente. Desse modo, para considerar os dados referentes ao tipo de documentos emitidos nas ações fiscais, foram considerados apenas os anos de 2015 a 2018.

Dentre as propriedades existentes, as ações fiscalizatórias foram desempenhadas de forma aleatória, partindo apenas da 
escolha dos municípios no intuito de abranger a totalidade da Regional ao longo dos anos, mas sem critérios pré-definidos para escolha de propriedades. Além disso, as ações foram desenvolvidas ao longo do ano, sem definição de um período específico para realização.

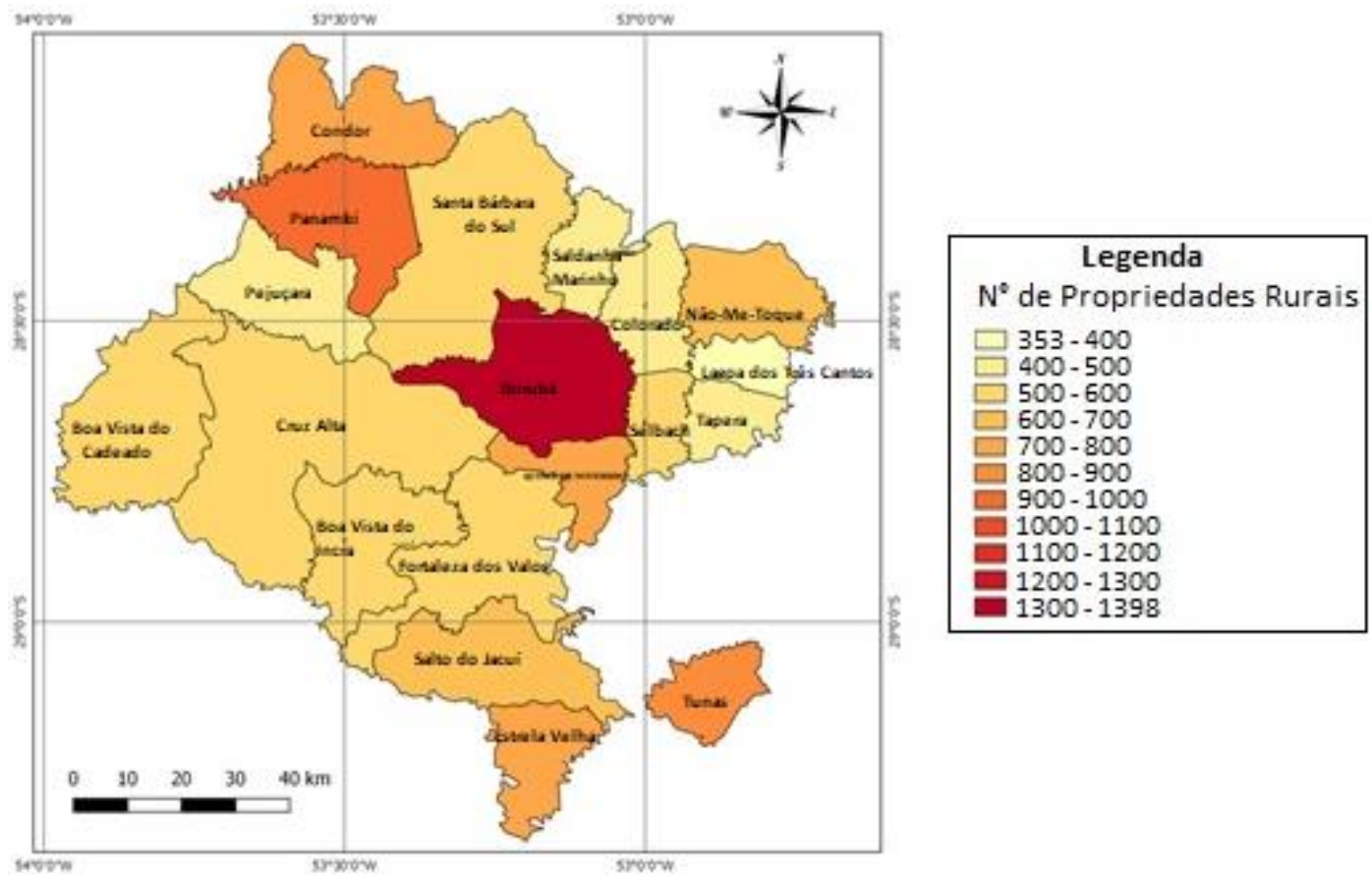

Figura 1. Distribuição do número de propriedades rurais por município da Regional de Cruz Alta, RS - SEAPDR.

Foram analisados os documentos fiscais emitidos pelos Fiscais Estaduais Agropecuários em fiscalização de uso de agrotóxicos e afins pela SEAPDR, do período de 2012 a 2018, sendo que as informações extraídas foram agrupadas por ano, abordando-se as seguintes questões: possui depósito de agrotóxicos; possui depósito de embalagens vazias; apresentou notas fiscais dos agrotóxicos; apresentou receituário agronômico; apresentou comprovante de devolução de embalagens vazias; havia reutilização de embalagens vazias; e se haviam agrotóxicos vencidos ou em desuso na propriedade.

Além dessas, foram apresentadas as infrações relacionadas ao uso de agrotóxicos, que motivaram os autos de infração emitidos no período pelos fiscais, sendo estas enquadradas conforme o manual de procedimentos para fiscalização do uso, comércio e prestação de serviços na aplicação de agrotóxicos e afins, e do comércio de sementes e mudas, da SEAPDR [12]. Os aspectos fiscalizados referem-se à fiscalização de uso de agrotóxicos considerando o disposto na Lei Federal 7.802/1989, no Decreto Federal 4.074/2002 e na Norma ABNT NBR 9843/2013 [13].

Os dados relativos aos produtos apreendidos, por encontrarem-se vencidos ou em desuso, foram apresentados em termos de quantidade, já os produtos não registrados no Ministério da Agricultura, Pecuária e Abastecimento (MAPA) foram agrupados por marca comercial, princípio ativo e país de origem. Após as avaliações, os dados coletados foram submetidos a uma análise exploratória por meio de estatística descritiva com uso de frequência percentual.

\section{Resultados e discussões}

Em relação ao tipo de documento fiscal emitido por ação fiscal de uso de agrotóxicos nas propriedades rurais fiscalizadas nos anos de 2015 a 2018 (Figura 2), observa-se que, os dois primeiros anos (2015 e 2016) apresentaram percentual maior de autos de infração, com $21,75 \%$ e $28,57 \%$ dos documentos oficiais emitidos, respectivamente, quando comparados aos anos subsequentes.

Nos anos de 2015/2016 e 2017/2018, Ritter, Silva e Russini [14], em estudo realizado com produtores rurais da região da Fronteira Oeste do Rio Grande do Sul em duas safras agrícolas, relataram que os resultados não apontaram redução das infrações de uma safra para outra.

Ao considerar as informações retiradas dos documentos fiscais emitidos de 2012 a 2018, pode-se constatar que $56,25 \%$ das 


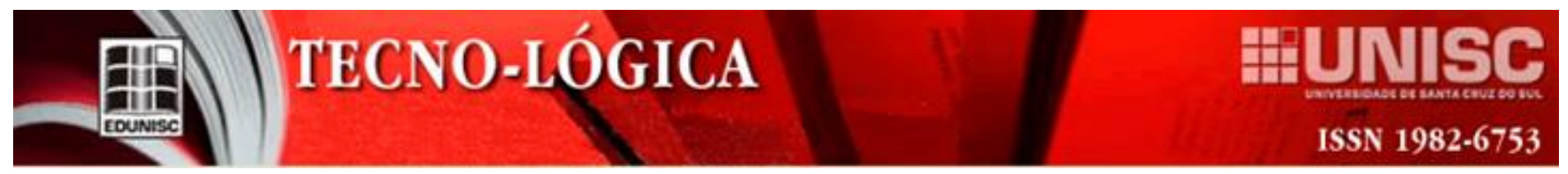

propriedades não possui depósito de agrotóxicos. Em sequência, destaca-se que, $54,17 \%$ não apresentaram comprovantes de devolução de embalagens vazias e receituários agronômicos; e $51,04 \%$ não apresentaram as notas fiscais no ato da fiscalização
(Figura 3). O armazenamento de agrotóxicos, dessa forma, apresenta-se como o problema mais frequente encontrado nas propriedades rurais da região.

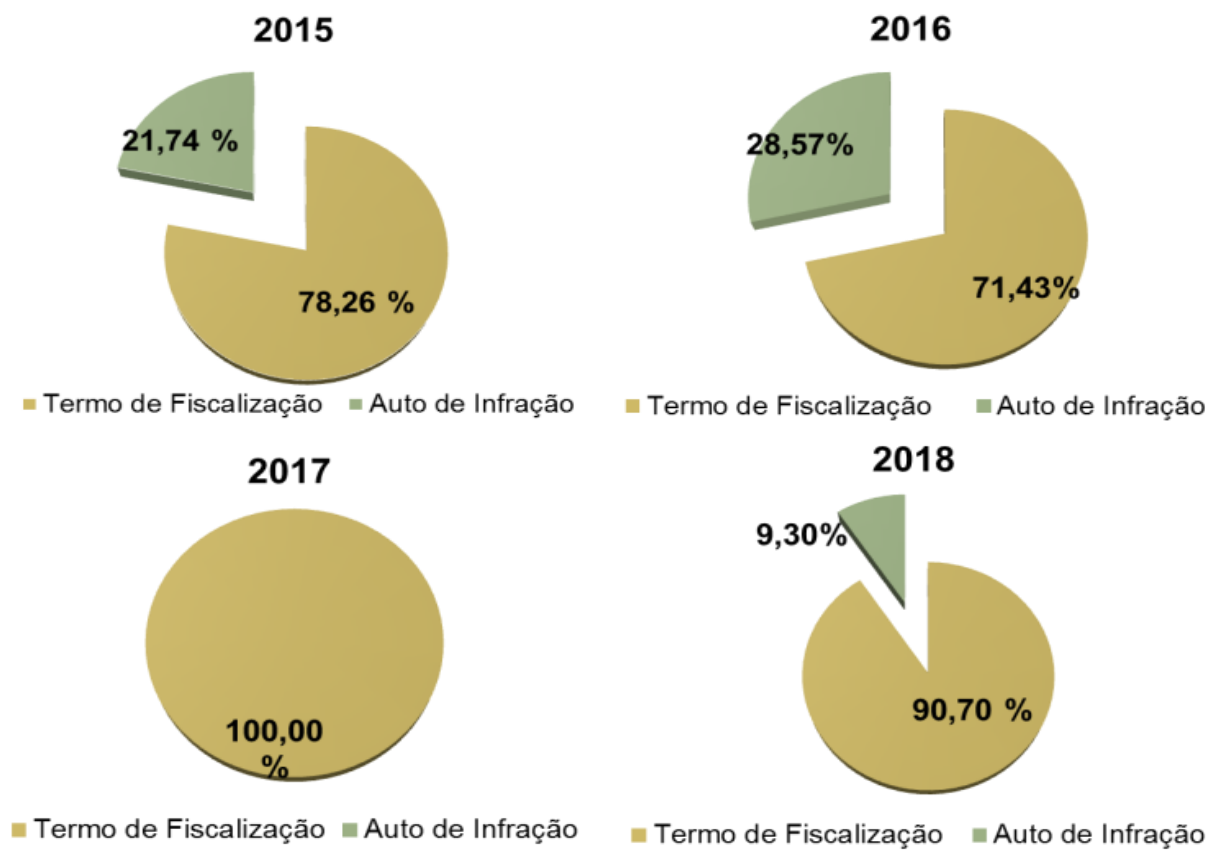

Figura 2. Tipo de documento fiscal emitido por ação fiscal de uso de agrotóxicos em propriedades rurais na Regional de Cruz Alta, RS - SEAPDR de 2015 a 2018.

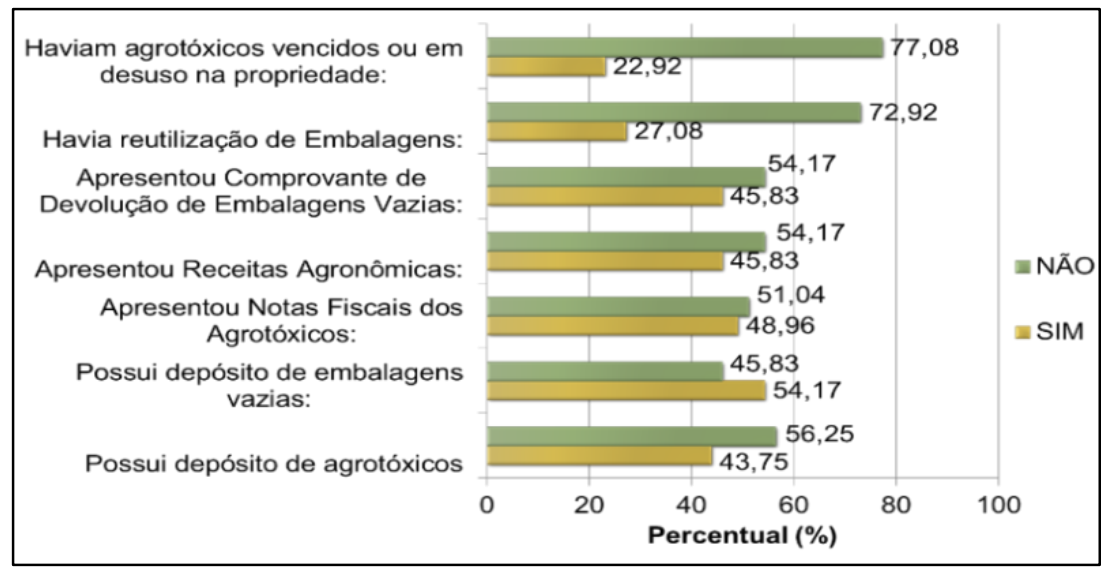

Figura 3. Itens fiscalizados e percentuais de propriedades rurais em desacordo e de acordo, na Regional de Cruz Alta, RS - SEAPDR, de 2015 a 2018. 
Comportamento semelhante ocorre na Fronteira Oeste do estado do RS, onde Ritter, Silva e Russini [14] relataram o mesmo ponto crítico, sendo que problemas com o armazenamento de agrotóxicos foram encontrados em $60,0 \%$ das propriedades da região na safra 2014/2015; e em 67,5\% na safra 2015/2016.

Monquero, Inácio e Silva [15] em levantamento do uso de agrotóxicos por pequenos e médios produtores rurais da região de Araras, SP constataram que 51,9\% dos entrevistados utilizam pavilhão não exclusivo para o armazenamento desses produtos, possibilitando o contato com outros produtos agrícolas. Sousa et al. [16] em estudo semelhante no Ceará, constataram que 70\% dos agricultores dizem deixar os agrotóxicos em armazéns, 13\% guardam em casa e $17 \%$ deixam no campo. No entanto, não há informações quanto às condições para o armazenamento de agrotóxicos em armazéns.

Abreu et al. [17] em estudo semelhante com agricultores familiares no município de Tartarugalzinho, AP afirmam que apenas $16 \%$ dos agricultores armazenam os defensivos agrícolas em local exclusivo. Abreu e Alonzo [18], em estudo sobre o uso de agrotóxicos por agricultores familiares no município de Lavras, MG, verificaram que, $88,9 \%$ dos agricultores entrevistados armazenam os agrotóxicos em uma construção independente; no entanto, destes, 41,9\% armazenam os produtos em construção de alvenaria com piso cimentado ou similar, sem goteira, bem ventilado e bem iluminado.

Já Shimokomaki e Costa [19], ao verificarem o armazenamento de agrotóxicos em fazendas certificadas de produção de café em Monte Carmelo, MG, com base na NR 31, constataram que $96,7 \%$ das fazendas possuem depósito de agrotóxicos construído em alvenaria e 83,3\% mantém o depósito fechado com chave. Diferente dessa realidade, Gomes, Araújo e Francelino [20] avaliaram o manejo de agrotóxicos no Vale do São Francisco no estado da Bahia, em produtores rurais com área média de 6,8 ha e constataram que apenas $0,9 \%$ dos entrevistados possuem local isolado e exclusivo para o armazenamento de agrotóxicos. Em 77,8\% dos casos os produtores rurais armazenam os agrotóxicos em local de alvenaria e coberto, 58,1\% com piso liso e impermeável; no entanto, 96,8\% dizem armazenar outros insumos agrícolas juntamente com os agrotóxicos.

Em estudo realizado por Pereira, Araújo e Labinas [21], avaliando o conhecimento dos produtores rurais do município de Arealva, SP sobre as regras para o uso de agrotóxicos, demonstrou-se que os agricultores do município estão cientes das regras e aspectos legais que tratam das exigências para um depósito de agrotóxicos, sendo que 84,6\% dos agricultores informaram saber que o depósito deve ser construído com material não combustível, piso impermeável, mureta para evitar vazamento, porta trancada e placa de advertência de "Cuidado Veneno", e que no depósito não podem ser guardados outros produtos, como: ferramentas, ração, peças, dentre outros. No mesmo estudo, $80 \%$ informaram saber das exigências quanto à ventilação, iluminação, isolamento para impedir entrada de animais e organização dos produtos no depósito.

Em relação ao local para o armazenamento das embalagens vazias, constatou-se que $45,83 \%$ das propriedades não possuem espaço adequado para depositá-las. Ritter, Silva e Russini [14] relataram que na Fronteira Oeste do RS, 21,3\% dos produtores não destinaram adequadamente as embalagens vazias na safra 2014/2015. Já na safra 2015/2016 o percentual subiu para 30\%. Sousa et al. [16] relataram que, 57\% dos produtores rurais informaram jogar as embalagens vazias de agrotóxicos a céu aberto e $33 \%$ informaram deixar dentro do armazém. No entanto, não há informação quanto às condições dos armazéns para depósito, não possibilitando a afirmação de que estas estariam acondicionadas corretamente.

O recolhimento das embalagens vazias passou a ser obrigatório no ano de 2000, após a promulgação da Lei Federal $\mathrm{n}^{\circ}$ 9.974/2000 que regulamenta a logística reversa das embalagens vazias de agrotóxicos, distribuindo as responsabilidades aos agricultores, comerciantes, fabricantes e ao poder público. De acordo com a legislação, o usuário final deve devolver as embalagens vazias de agrotóxicos no prazo de um ano, no endereço do posto ou central de recolhimento indicado na nota fiscal de compra do agrotóxico.

Pereira, Araújo e Labinas [21] demonstraram que 15,4\% dos produtores rurais, quando perguntados sobre onde devem ser guardadas as embalagens vazias de agrotóxicos, responderam que deve ser em um local coberto para evitar o acúmulo de água da chuva, sendo que $76,9 \%$ responderam que devem ser guardadas no depósito de agrotóxicos. Gomes, Araújo e Francelino [20] afirmam que, $31,3 \%$ dos produtores rurais informaram que foram orientados pelo vendedor de agrotóxicos, no ato da compra do produto, sobre os procedimentos para o acondicionamento, armazenamento e transporte de embalagens vazias.

Em relação aos comprovantes de devolução de embalagens vazias, receituários agronômicos e notas fiscais requisitados no ato da fiscalização, $54,17 \%$ dos produtores fiscalizados não apresentaram comprovantes de devolução nem receituários e $51,04 \%$ não apresentaram as notas fiscais. Ritter, Silva e Russini [14] verificaram que $18,8 \%$ dos produtores não apresentaram os receituários na primeira safra e $15 \%$ na segunda, sendo que $2,5 \%$ não apresentaram os comprovantes de devolução de embalagens vazias na primeira safra e $7,5 \%$ na segunda.

O fato de os produtores não fornecerem os receituários agronômicos, notas fiscais e comprovantes de devolução de embalagens vazias no ato da fiscalização reflete o hábito que estes possuem de não guardar tais documentos, ou então de não guardálos de forma organizada, além dos produtores que afirmam encaminhar a documentação aos seus escritórios de contabilidade, e outros que afirmam não receber o receituário agronômico no ato da compra.

Corroborando com isto, Sousa et al. [16] relataram que, $73 \%$ dos produtores entrevistados afirmaram nunca terem 
recebido o receituário agronômico. Abreu et al. [14] em estudo no Amapá constataram que, $92 \%$ dos agricultores adquirem agrotóxicos sem a apresentação de receituário agronômico. Realidade distinta é relatada por Abreu e Alonzo [18], onde 78,4\% dos agricultores de Lavras, $\mathrm{MG}$ informaram receber a o documento, no momento da aquisição de agrotóxicos.

Conforme consta no Decreto Federal $n^{\circ} 4.074 / 2002$, os receituários agronômicos devem ficar à disposição da fiscalização por um prazo mínimo de dois anos e os comprovantes de devolução de embalagens vazias por no mínimo um ano. Estudo feito por Pereira, Araújo e Labinas [21] demonstraram que, 29,2\% dos produtores entrevistados informaram o prazo correto que o comprovante de devolução deve ser guardado, e 44,6\% informaram um prazo maior, sabendo, portanto, que o comprovante deve ser guardado.

Mecabo [22] afirmou que, 94,6\% dos produtores sabem da importância de realizar a devolução das embalagens vazias de agrotóxicos. No entanto, Gomes, Araújo e Francelino [20] demonstraram um resultado preocupante no estado da Bahia, afirmando que, no ano de 2014, 99,7\% dos produtores informaram que o percentual de embalagens vazias recolhidas não ultrapassou $10 \%$ do total de agrotóxicos comprados. Abreu et al. [14], no Amapá, afirmaram que, $68 \%$ dos agricultores queimam as embalagens vazias e $16 \%$ enterram ou dão outro destino. Abreu e Alonzo [18] relataram que, 53,1\% dos agricultores no município de Lavras, MG, devolvem as embalagens vazias, enquanto que $45,7 \%$ fazem a queima destas.

Quanto à reutilização de embalagens vazias, em 27,08\% das propriedades foi verificada alguma forma de reutilização de embalagens, utilizando estas para coletar óleo queimado, como caixa armazenadora de parafusos e peças diversas, e bebedouros de animais. Pereira, Araújo e Labinas [21] relataram que, 76,9\% dos produtores informaram saber que não podem reutilizar as embalagens vazias. Mecabo [22] relata que, apenas 3,6\% de produtores reutilizam embalagens vazias; já, Gomes, Araújo e Francelino [20] um percentual de 0,3\%.

Em relação aos agrotóxicos vencidos ou em desuso, foi verificado que em $22,92 \%$ das propriedades haviam agrotóxicos vencidos ou em desuso, totalizando $6.235,11 \mathrm{~kg}$ de agrotóxicos vencidos ou em desuso apreendidos em fiscalização de uso de 2015 a 2018. Muitos dos produtores informaram não saber o que fazer com os produtos em desuso ou vencidos, e outros relataram que utilizariam os produtos mesmo estando vencidos. Shimokomaki e Costa [19] em avaliação do uso de agrotóxicos em propriedades certificadas produtoras de café verificaram que, 96,7\% das propriedades realizam a destinação dos produtos vencidos aos fabricantes ou fornecedores. Pereira, Araújo e Labinas [21] relataram que, 61,5\% dos produtores sabiam que os produtos vencidos devem ser devolvidos aos fabricantes, e 73,6\% disseram saber que os produtos vencidos devem ficar no depósito de agrotóxicos, identificados e separados dos demais.

Quanto às infrações apontadas em Autos de Infração pela SEAPDR, foram autuadas $13,54 \%$ das propriedades fiscalizadas entre os anos de 2015 a 2018, pelos seguintes motivos: Manipular, importar, comercializar ou utilizar agrotóxicos e afins não registrados no MAPA (ilegais e banidos) (70,59\% das autuações); Usuário de agrotóxicos e afins que proceder em desacordo com o receituário agronômico e/ou com as recomendações do fabricante constantes em rótulo e bula $(11,76 \%)$; Desobediência às determinações do órgão competente $(11,76 \%)$ e Não destinar adequadamente as embalagens vazias de agrotóxicos e afins ou reutilizá-las $(5,88 \%)$, conforme demonstra a figura 4 .

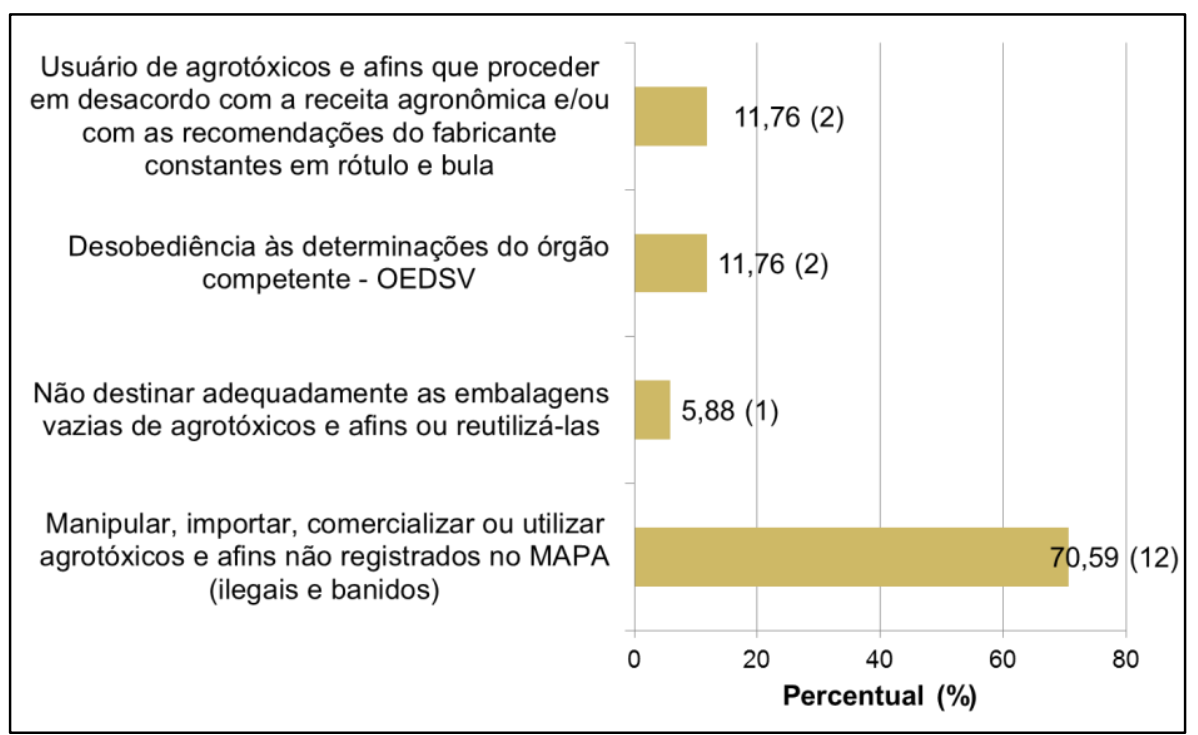

Figura 4. Infrações apontadas em Autos de Infração e percentual de propriedades rurais autuadas na Regional de Cruz Alta, RS - SEAPDR, de 2015 a 2018. 
Conforme observado na Figura 4, a infração de manipular, importar, comercializar ou utilizar agrotóxicos e afins não registrados no MAPA é o motivo da grande maioria dos Autos de Infração emitidos pela SEAPDR na Regional de Cruz Alta, RS, correspondendo a 70,59\% dos casos. Ao considerar o total de propriedades fiscalizadas, percebe-se que o uso de agrotóxicos não registrados no MAPA foi constatado em 11,77\% das propriedades. Ao verificar os agrotóxicos contrabandeados, Grasseli e Pereira [23], com base nos Autos de Infração lavrados pela SEAPDR em 2011, constataram que, das 345 ações de fiscalização do comércio e uso de agrotóxicos, 14,20\% resultaram em infração relacionada aos agrotóxicos sem registro no MAPA, sendo que 81,62\% destas, resultantes de fiscalizações de uso de agrotóxicos. Já, Ritter, Silva e Russini [14] verificaram apenas duas ocorrências desta natureza, representando 2,5\% dos agricultores fiscalizados na região da Fronteira Oeste gaúcha.

Horri [24], ao considerar o total de consumo de agrotóxicos no Brasil, constatou uma média de $9 \%$ de uso de agrotóxicos ilícitos no período de 2008 a 2012. Barbosa e Vasconcelos [25] relatam que, em audiência pública da Comissão da Reforma Agrária do Senado, em novembro de 2016, Fernando Figueiredo, presidente-executivo da Associação Brasileira da Indústria Química, afirmou que mais de $20 \%$ dos agrotóxicos consumidos no Brasil são ilegais.

A preocupação com esses dados deve-se ao fato de que, além de produtos proibidos, entram no país produtos de baixa qualidade que não tiveram sua eficiência agronômica testada e não passaram por avaliações toxicológicas e de periculosidade ao meio ambiente [26]. Fraga et al. [27] ressaltam ainda que, por não haver controle dessas substâncias, a eficiência agronômica pode estar abaixo do esperado e gerar prejuízos aos agricultores, além de contaminar as culturas e o meio ambiente, podendo levar aos problemas de saúde pública e ambientais. Lemos; Carvalho e Ortiz [28] afirmaram que, $18 \%$ dos produtos apreendidos e analisados quimicamente pela Polícia Federal eram falsificados, não apresentando nenhum princípio ativo ou princípios ativos diferentes dos descritos na embalagem.

Na Regional de Cruz Alta foram apreendidos 15 produtos comerciais distintos de agrotóxicos sem registro no MAPA, sendo estes compostos por oito princípios ativos diferentes (Figura 5). Em destaque o princípio ativo metsulfurom-metil, que corresponde a $40 \%$ dos casos, seguido pelo imidacloprido $(26,67 \%)$ e tebuconazol e fipronil $(13,33 \%$ cada). Grasseli e Pereira [23] também relataram o metsulfuron-metilico $(20,37 \%)$, como predominante, seguido do imidacloprido, clomazona e friponil (9,26\% cada) e imazetapir (7,40\%). Lemos; Carvalho e Ortiz, [28] afirmaram que, a análise dos laudos periciais dos agrotóxicos contrabandeados apreendidos revelou que o metsulfurom-metílico foi o princípio ativo encontrado, seguido pelo imidacloprido, benzoato de emamectina e fipronil que, juntos, somaram $44 \%$ das apreensões.

Quanto à origem dos produtos apreendidos, verificou-se que, $66,67 \%$ são oriundos do Uruguai, 13,33\% do Paraguai e 20\% de origem não identificada. Grasseli e Pereira [23] relataram que $79,63 \%$ dos agrotóxicos apreendidos pela SEAPDR em 2011 eram oriundos do Uruguai. Dorfman, França e Soares [29] afirmam que o comércio ilegal de agrotóxicos no Brasil surge principalmente na fronteira com o Uruguai, devido ao grande diferencial em termos de legislação e preço entre os dois países, que chega a ser $50 \%$ menor do que os nacionais. Souza et al. [26] relataram que o Paraguai é responsável pela maior parte dos agrotóxicos contrabandeados na maioria dos estados brasileiros. No caso do estado do Rio Grande do Sul, no entanto, este lugar é ocupado pelo Uruguai.

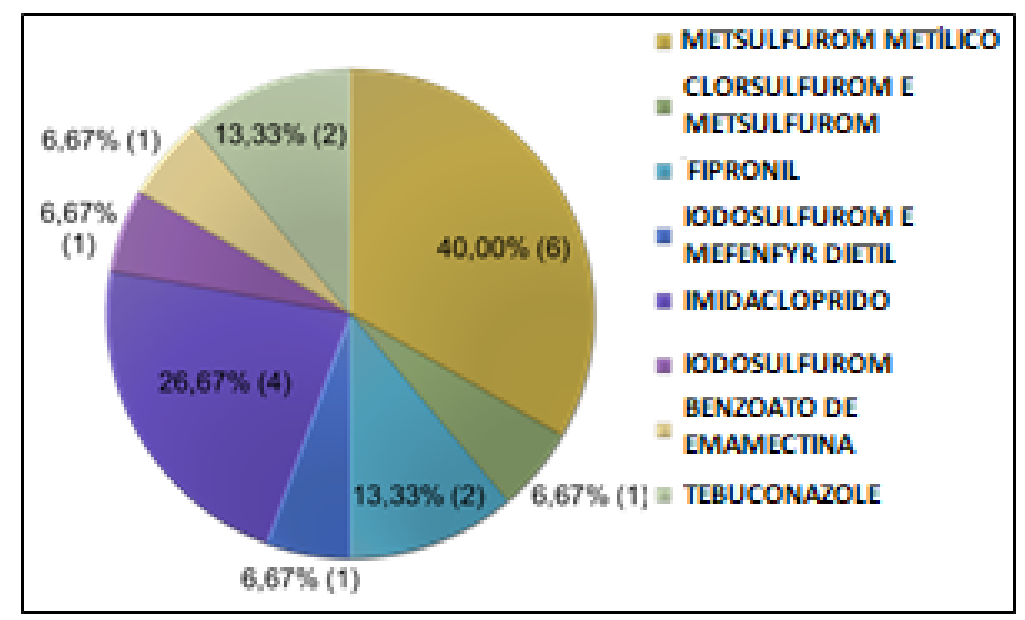

Figura 5. Percentual por princípio ativo de agrotóxicos sem registro no MAPA apreendidos pela SEAPDR na Regional de Cruz Alta, no período de 2015 a 2018. 


\section{Conclusões}

Os maiores problemas observados nas propriedades rurais fiscalizadas da regional de Cruz Alta, RS, quanto à legislação vigente para o uso de agrotóxicos foram: a falta de depósito de agrotóxicos exclusivo para este fim; a falta do hábito de guardar os receituários agronômicos, notas fiscais e comprovantes de devolução das embalagens vazias na propriedade rural pelo período exigido por lei e a falta de um depósito para armazenar as embalagens vazias de agrotóxicos.

A infração com maior incidência, motivando a maior parte dos Autos de Infração foi a de manipular, importar, comercializar ou utilizar agrotóxicos e afins não registrados no MAPA (ilegais e banidos).

Portanto, ações de orientação e fiscalização, assim como atividades de educação sanitária realizadas com maior frequência na região têm o intuito de auxiliar os produtores rurais a adequarem-se às normas vigentes, reduzindo os riscos de contaminação dos usuários, dos alimentos e do meio ambiente.

\section{Agradecimentos}

Os autores agradecem à Secretaria da Agricultura, Pecuária e Desenvolvimento Rural - SEAPDR.

\section{FISCALIZATION ACTION OF THE USE OF AGROCHEMICALS ON RURAL PROPERTIES IN THE REGION OF CRUZ ALTA - RIO GRANDE DO SUL}

ABSTRACT: As provided in Article 10 of Federal Law 7802/89, it is the responsibility of the states to supervise the use, consumption, commerce, storage and internal transportation of pesticides. In this context, the objective of this work is to present an evaluation of the control of the use of agrochemicals and similar, and the compliance with the legislation on rural properties in the region of Cruz Alta-RS within the Secretariat Agriculture, Livestock and Rural Development. We analyzed the tax documents issued by State Agricultural and Forestry Inspectors in the inspection of the use of pesticides and similar products by Secretariat Agriculture, Livestock and Rural Development, from the period of 2012 to 2018 . The major problems encountered in the rural properties of the region are the lack of exclusive pesticide deposit for this purpose; lack of habit of storing agronomic receipts, invoices and proof of return of empty containers; and the lack of a warehouse to store the empty pesticide containers. The most important infraction was to manipulate, import, market or use pesticides and related products not registered in Ministry of Agriculture, Livestock and Food Supply (illegal and banned). In view of the above scenario, guidance and inspection actions are justified, as well as sanitation education activities that are more frequent in rural properties in the region.
Keywords: Agricultural fiscalization. Use of pesticides. Law of pesticides. Illegal pesticides.

\section{Referências}

[1] MATA, J. S.; FERREIRA, R. L. Agrotóxico No Brasil - Uso e Impactos ao Meio Ambiente e a Saúde Pública. Ecodebate, 02 ago. 2013. Disponível em: <https://www.ecodebate.com.br/2013/08/02/agrotoxico-no-brasil-uso-e-impactosao-meio-ambiente-e-asaude-publica-por-joao-siqueira-da-mata-e-rafael-lopesferreira/>. Acesso em: 22 de abril de 2019

[2] SIQUEIRA, D. F. et al. Análise da exposição de trabalhadores rurais a agrotóxicos. Rev. Bras. Prom. Saúde. V. 26 (2), p. 182-191. 2013.

[3] SERRA, L. S. et al. Revolução Verde: reflexões acerca da questão dos agrotóxicos. Revista Científica do Centro de Estudos em Desenvolvimento Sustentável da UNDB. V. 1, n. 4, jan/julho 2016.

[4] VALENZUELA, P. M. et al. Pediatra ambiental: um tema emergente. J. Pediatr., Rio de Janeiro, v. 87, n. 2, p.89-99, 2011

[5] SOUZA, L. C. Análise da legislação sobre agrotóxicos no Brasil: Regulação ou desregulação do controle de uso? Revista Jurídica ESMP-SP, v. 11, p. 41-74, 2017.

[6] FRANCO, C. R.; PELAEZ, V. Antecedentes da lei federal de agrotóxicos (7.802/89): o protagonismo do movimento ambientalista no Rio Grande do Sul. International Scientific Journal, v. 12, n. 4, art. N. 3, out.-dez./2017.

[7] RigotTo, R. M.; VASCONCElOS, D. P.; ROCHA, M. M. Uso de agrotóxicos no Brasil e problemas para a saúde pública. Cad. Saúde Pública. v. 30(7): p.1-3, 2014.

[8] IBAMA - INSTITUTO BRASILEIRO DO MEIO AMBIENTE E DOS RECURSOS NATURAIS RENOVÁVEIS. Boletins anuais de produção, importação, exportação e vendas de agrotóxicos no Brasil - Boletim Anual 2017. Disponível em: https://www.ibama.gov.br/agrotoxicos/relatorios-decomercializacao-de-agrotoxicos\#boletinsanuais. Acesso em: 24 de abril de 2019.

[9] BARROSO, L. B.; WOLFF, D. B. Riscos e segurança do aplicador de agrotóxicos no Rio Grande do Sul. Disc. Scientia. Série: Ciências Naturais e Tecnológicas, Santa Maria, v. 10, n. 1, p. 27-52, 2009.

[10] IBGE - INSTITUTO BRASILEIRO DE GEOGRAFIA E ESTATÍSTICA. SIDRA - Banco de Tabelas Estatísticas. 2017. Disponível em: https://sidra.ibge.gov.br/Tabela/1612. Acesso em: 24 abril de 2019.

[11] IBGE - INSTITUTO BRASILEIRO DE GEOGRAFIA E ESTATÍSTICA Censo Agropecuário $2006 . \quad$ Disponível em: <https://www.ibge.gov.br/estatisticas/economicas/agricultura-e-pecuaria/218142017-censo-agropecuario.html?=\&t=o-que-e>. Acesso em: 24 abril de 2019.

[12] SEAPDR - SECRETARIA DA AGRICULTURA, PECUÁRIA E DESENVOLVIMENTO RURAL. Manual de procedimentos para fiscalização do uso, comércio e prestação de serviços na aplicação de agrotóxicos e afins, e do comércio de sementes e mudas. 2017. Disponível em: https://www.agricultura.rs.gov.br/agrotoxicos-2016-12. Acesso em: 22 de abril de 2019.

[13] ABNT - ASSOCIAÇÃO BRASILEIRA DE NORMAS TÉCNICAS. NBR 9843-3: Armazenamento em propriedades rurais. Rio de Janeiro, 2013. 4 p.

[14] RITTER, J. G.; SILVA, F. F.; RUSSINI, A. Ação fiscalizatória e adequação da indicação, comércio e uso de agrotóxicos por agricultores da Fronteira Oeste do Rio Grande do Sul. TECNO-LÓGICA, Santa Cruz do Sul, v. 22, n. 1, p. 50-57, jan./jun. 2018. 
[15] MONQUERO, P. A.; INÁCIO, E. M.; SILVA, A. C. Levantamento de agrotóxicos e utilização de equipamento de proteção individual entre os agricultores da região de Araras. Arq. Inst. Biol., São Paulo, v.76, n.1, p.135-139, jan./mar., 2009 .

[16] SOUSA, J. A. et al. Percepção dos produtores rurais quanto ao u so de agrotóxicos. Rev. Bras. Agric. Irr. Fortaleza, v. 10, nº 5, p. 976 - 989, Set - Out, 2016.

[17] ABREU, V. S. S. et al. O uso de agrotóxicos nas propriedades de agricultores familiares do município de Tartarugalzinho, estado do Amapá. Cadernos de Agroecologia. Resumos do IX Congresso Brasileiro de Agroecologia - Belém/PA, Belém, Vol 10, N 3, out 2015.

[18] ABREU, P. H. B.; ALONZO, H. G. A. O agricultor familiar e o uso (in)seguro de agrotóxicos no município de Lavras/MG. Revista Brasileira de Saúde Ocupacional, São Paulo, vol. 41, p. 1 -12, 2016.

[19] SHIMOKOMAKI, F. K.; COSTA, C. Verificação de armazenamento de defensivos agrícolas em fazendas certificadas de café em monte Carmelo-MG. GETEC, v.7, n.15, p.103 - $114 / 2018$.

[20] GOMES, V. E. V.; ARAÚJO, R. C. P.; FRANCELINO, I. V. manejo dos agrotóxicos e das suas embalagens vazias em propriedades rurais no estado da Bahia. Atas de Saúde Ambiental, São Paulo, V. 6, p. 46-70, jan-dez, 2018.

[21] PEREIRA, R. M.; ARAÚJO, M. C.; LABINAS, A. M. O conhecimento de produtores rurais do município de Arealva, SP, Brasil sobre as regras de uso dos agrotóxicos. Rev. Ambient. Água, Taubaté, vol. 11 (suplemento), p. 1207-1216, 2016.

[22] MECABÔ, C. V. O conhecimento da logística reversa e as responsabilidades na devolução das embalagens vazias de agrotóxicos. R. gest. sust. ambient., Florianópolis, v. 7, n. 1, p. 539-558, jan./mar. 2018.

[23] GRASSELI, R. C. A.; PEREIRA, F. M. D. Agrotóxicos contrabandeados apreendidos pela fiscalização agropecuária no Rio Grande do Sul em 2011. Banner arquivo SEAPDR, 2011.

[24] HORRI, A. K. D. nas fronteiras do ecúmeno: a teritorialização da rede do contrabando de agrotóxicos no Paraná (Brasil)-Paraguai. Geographia Opportuno Tempore, Londrina, v. 2, n. 1, p. 59-75, jan./jul. 2015.

[25] BARBOSA, A. A.; VASCONCELOS, P. E. A. Os impactos do uso de agrotóxicos e as consequências na sociedade e na legislação brasileira. Revista Jurídica Direito, Sociedade e Justiça/RJDSJ, Dourados, v. 6, n. 1, p. 331-333, mar.jun./2018.

[26] SOUZA, D. Z. et al. Agrotóxico no Rio Grande do Sul: o grave problema do contrabando. Toxicovigilância - Toxicologia Clínica: dados e indicadores selecionados Rio Grande do Sul 2008-2009. V. 4, p. 19-27, 2009.

[27] FRAGA, W. G. et al. Identificação dos principais ingredientes ativos em agrotóxicos ilegais apreendidos pela Polícia Federal do Brasil e quantificação do Metsulfurom-metílico e Tebuconazol. Rev. Virtual Quim. 8(3), 561-575, 2016.

[28] LEMOS, V. F.; CARVAlHO, A. C. B.; ORTIZ, R. S. Perfil nacional de apreensões de agrotóxicos pela Polícia Federal. Rev. Bras. Crimin. 7(1), 21-25, 2018.

[29] DORFMAN, A.; FRANÇA, A. B. C.; SOARES, G. O. Marcos legais e redes de contrabando de agrotóxicos: análise escalar a partir da fronteira Brasil-Uruguai. Revista Terr@Plural, Ponta Grossa, 8(1),p. 37-53, 2014. 